\title{
Comparison of anthropometric characteristics between world tour and professional continental cyclists
}

\author{
Joshua M Miller. ${ }^{1} \bowtie$, Kyle J Susa ${ }^{2}$
}

\begin{abstract}
This study analyzed the physical characteristics of the World Tour (WT) and Professional Continental (PC) cyclists during the 2017 racing season. Seven hundred and ten professional riders (mean \pm SD: $27.9 \pm 4.2$ years, $1.81 \pm 0.06$ $\mathrm{m}, 68.6 \pm 6.33 \mathrm{~kg}$ ) were compared for physical characteristics (i.e. age, height, and body mass). The top $25 \%$ within rider specialties were selected as the sample group based upon Pro Cycling Stats points General Classification, sprinter, time-trialists, one-day racer earned during the previous season. An additional rider classification was created for those riders outside of the top $25 \%$ of all categories called Domestique. General Classification riders in the WT were older than PC, however, there were no other differences between rider specialties. However, differences were found in anthropometric characteristics within the different divisions (i.e. height, body mass, body surface area, and frontal area). In conclusion, the present study identified specific physical characteristic differences between the different types of professional cyclist levels of riders (WT vs. PC) and within their specialty of rider, which may determine when a rider may move to the WT from the PC.
\end{abstract}

Keywords: body dimensions; body surface area; frontal area; cyclists

Contact email: imiller68@csub.edu (JM Miller)

${ }^{1}$ Department of Kinesiology, California State University, Bakersfield,

Bakersfield, California, USA

${ }^{2}$ Department of Psychology, California State University, Bakersfield,

Bakersfield, California, USA

Received: 05 September 2018. Accepted: 25 November 2018.

\section{Introduction}

Professional road cycling is a sport that is dependent upon specific characteristics of the rider. Within professional cycling there are two main divisions of teams, World Tour (WT) and Pro Continental (PC) cycling teams. The differences between the two divisions include: 1) WT teams are capped at a maximum of 18 teams, while in contrast there is no limit to the total number of PC teams; 2) WT teams are invited to the races that are higher caliber and prestigious, in contrast the PC teams earn an invitation to these races and all are not invited; 3) WT and PC teams are invited to smaller races with Continental teams; and 4) at lower division races the WT teams are not invited, but PC, Continental, and national teams are invited. Each team is made up of different riders, including sprinters (S), one-day riders (OD), time trialists (TT), domestiques (D), and general classification (GC), with the goal of winning the race with the rider that best fits characteristics of the particular race or stage on that day.
Each race requires riders to perform in a variety of different terrains (i.e. flat courses, mountain passes, and long multiple terrains) and in different situations (i.e. in the group, off in a break, or acting as a helper to the team leader). Success of the rider has been shown to depend upon specific anthropometric variables $[1,2]$. Body surface area and frontal area are two of the most important performance-determining anthropometric variables of success in the different specialties $[3,4]$.

Previous research has reported that the anthropometric values may be greatly different depending upon the rider's specialty. Time-trialists or sprinters are usually taller and heavier, in comparison to climbers $[2,5,6]$. Mujika and Padilla reported body mass for the different specialties in uphill, all terrain, and time-trial and flat terrain specialists, respectively [7]. In addition, climbers also have a significantly smaller BSA and FA for uphill, all terrain, and time-trial and flat terrain specialists, respectively $[1,2,5,8]$.

Several investigations have studied the relationships between anthropometric variables in professional cyclists $[1,2,5,8]$. Pro Continental teams are similar to those of the WT. The PC riders that are employed by the team previously could have ridden in the WT or may have moved up from the amateur ranks in order to become a professional rider. Road cycling is a sport that is affected by different variables (i.e. physiological characteristics, technical and tactical abilities), and thus differences may exist between the WT and PC racing divisions. Until now, however, no study has looked at the difference between World Tour and Pro-Continental riders. It was thus the purpose of 
this study to evaluate the anthropometric variables in relation to their status as a professional road cyclist.

\section{Methods \\ Subjects}

Riders with contracts in the World Tour (WT) and Pro-Continental (PC) levels during the 2017 racing calendar year were analyzed for this study. The groups consisted of $18 \mathrm{WT}$ teams with a total of 478 riders and $27 \mathrm{PC}$ teams with a total of 499 riders with a sample of 977 riders. The final sample of 321 professional cyclists (185 WT and 136 PC) met the inclusion criteria of: a) inclusion of height and weight data; b) Pro Cycling Stats (PCS) Ranking points: and c) points based upon specialty. The Institutional Review Board at California State University, Bakersfield approved the study prior to data collection.

\section{Methodology}

\section{Morphologic Variables}

Data was gathered from the PCS

webpage (www.procyclingstats.com). This website maintains a database on the men's WT and PC, and the UCI Women's teams. The specific data that was gathered for each rider in the WT and PC included the following points: a) height in $\mathrm{m}$; b) body mass in $\mathrm{kg}$; c) calculated body mass index (BMI; body weight in $\mathrm{kg} /$ height in $\mathrm{m}$ squared $\left(\mathrm{kg} / \mathrm{m}^{2}\right)$; and $\left.\mathrm{d}\right)$ the specialty category with the most PCS points (i.e. OD, TT, GC, and $\mathrm{S})$. The remaining riders were placed into a fifth category called Domestique (D) (Tables 1-2).

\section{Body Surface Area and Frontal Area}

Body surface area (BSA in $\mathrm{m}^{2}$ ) was determined from each cyclist's body mass and height, as described by Du Bois and Du Bois [9]:

$$
\mathrm{BSA}=0.007184 \cdot \mathrm{BM}^{0.425} \cdot \mathrm{H}^{0.725}
$$

in which $\mathrm{BM}$ is body mass $(\mathrm{kg})$, and $\mathrm{H}$ is height $(\mathrm{cm})$.

An assumption that frontal area (FA) can be considered relational to BSA [3], and based on previously measured values $[4,10]$, the value of FA was considered to be $18.5 \%$ of BSA.

\section{Rider Points and Classification}

The top $25 \%$ of riders were selected from each category based upon their highest specialty PCS points (GC, OD, $\mathrm{S}$, and TT). Additionally, the remaining riders were placed into a fifth category called Domestique (D). The D were selected as the lowest $25 \%$ to ensure that these riders would meet the characteristics of being a domestique or helper rider for the team captain or captain on the road.
Procycling stats has created their own scoring system. Each race is ranked (e.g. GT.B, 1.WT.A, 1.WT.C) and points are allocated based upon finishing place in the race or stage and time-trial place (Bert Lip, personal communication November 19, 2018). In a Grand Tour (GT) (i.e. Tour de France), points are based upon overall winner, stage winner, and placing in the time-trial. Scoring for the Tour de France, the overall winner is scored 400 points up to the $35^{\text {th }}$ receives 20 points. The riders are also receive points for winning the stage to $15^{\text {th }}$ place ranging between 80 to 1 point. Finally, TT points range from 40 to 8 points for first to fifth place riders. Individual GT stages (maximum points per stage is 80 ) are worth less than Monuments (Milan-San Remo, Tour of Flanders, Paris-Roubaix, Liege-Bastogne-Liege, and Il Lombardia) (maximum points for the winner is 275) and other one-day classics (i.e Strade Bianche, GentWevelgem, Amstel Gold Race, La Fleche Wallonne, and others) (maximum points for the winner is 275), but final tour GC results for Grand Tours (Tour de France, Giro d'Italia, and Vuelta Espana) are worth a more while GC results for one-week stage races (e.g. Criterium du Dauphine, Paris-Nice, Tour de Suisse) (maximum points for winner is 275) are roughly equivalent to a Monument race.

\section{Statistical Analysis}

The data were managed using SPSS version 21 (IBM, Armonk, New York) and analyzed with parametric statistics. A two-way factorial ANOVA, 2 (professional division: WT vs. PC) x 5 (rider specialty: TT, GC, OD, S, D) was performed and LSD pairwise comparisons were examined to determine if significant 
differences occurred. Differences were regarded as statistically significant if $p<0.05$.

\section{Results}

Results of the two-way factorial ANOVA indicated WT riders were significantly older than PC riders overall. However, no significant differences between WT and PC riders were found in height, weight, BMI, BSA, FA, $\mathrm{BSA} \cdot \mathrm{BM}^{-1}$ or $\mathrm{FA}^{-} \mathrm{BM}^{-1}$ for any of the rider specialty classes. All descriptive statistics for both divisions are found in Tables 1 and 2 .

We also compared differences between rider specialties in each of the divisions. Here, several similarities and a number of differences were found between WT and PC cyclists. With regard to age, TT were younger than $\mathrm{GC}$, and $\mathrm{D}$ riders in the WT division. However, TT riders were only younger than OD riders in the PC division. Further, in the $\mathrm{PC}$ division $\mathrm{S}$ and $\mathrm{D}$ riders were significantly younger than OD riders.

In terms of height, TT and D riders were taller than GC riders, and D riders were taller than OD riders, in the WT division. However, in the PC division TT riders were taller than OD and S riders. With regard to weight, GC riders were significantly lighter than all other riders in the WT division and all other riders except $\mathrm{S}$ riders in the $\mathrm{PC}$ division.

For BMI, there was much similarity between the two divisions. GC riders had a significantly lower BMI than all other riders, in each of the divisions. Also in both divisions, $\mathrm{S}$ had a higher BMI than D riders. OD had a higher BMI than D riders in the WT division, while $\mathrm{S}$ had a higher BMI than TT, and D in the PC division.

We also examined differences between BSA and FA; since these two metrics are strongly correlated the pattern of results was the same for both metrics. Here results indicated that in the WT division GC riders had less area than all other riders, while in the PC division they were only found to have less area than TT and D riders.

Finally, we examined the differences in $\mathrm{BSA} \cdot \mathrm{BM}^{-1}$ and $\mathrm{FA} \mathrm{BM}^{-1}$. These ratios are also highly correlated and were found to exhibit similar results in both divisions. Here, results indicated that GC riders had significantly higher $\mathrm{BSA} \cdot \mathrm{BM}^{-1}$ or $\mathrm{FA} \cdot \mathrm{BM}^{-1}$ than all other riders in both the WT and PC divisions.

\section{Discussion}

The present study aimed to evaluate the differences in anthropometric parameters of the different specialties in the World Tour and Professional Continental cyclists. Additionally, within each division a comparison of physical characteristics was performed between specialties of riders. Since these cyclists are professionals in their field, the rider should have adapted to the challenges of their particular specialty. The results could be useful to identify early talents or generate training programs for the cyclist.

Previous studies have demonstrated that a rider's specialty may be described by their physique [8]. Time trialists are traditionally heavier and taller than other riders, climbers are the lightest and shortest riders on a team, and flat terrain riders are tall and heavier than other riders [7, 11]. Body mass has a large impact on the riders abilities to ride uphill since it determines gravitydependent resistance. Whereas, FA influences riders aerodynamic resistance on level roads and riders will benefit from being larger than those specialties that are dependent upon being small and as light as possible. Padilla et al reported that the uphill (UH) athletes were significantly lighter, had a lower BSA and FA when compared to flat terrain (FT) and TT [2]. Menaspa et al. reported differences in male road junior cyclists of different specialties (i.e. UH, FT, AT, S)[1].

Concerning the adaptations resulting from cycling, we expected a certain body shape (e.g. taller and heavier for TT, shorter and lighter for the GC) of the riders in both divisions, when compared between the different specialties. We found similarities amongst the riders with previous studies $[2,5-7,11,12]$. Time Trialists were the tallest riders, and the GC riders were slightly shorter. Padilla et al. and Lucia et al. reported the climbers (UH) were shorter, this is similar to our study in that most GC contenders are riders that are able to climb very well in races like the Tour de France, Giro d'Italia, and Vuelta Espana $[2,5,11]$. Body mass was also the lowest in the GC riders compared to the other disciplines in both divisions, which was similar to previous studies $[2,5,11]$. This lighter weight has been considered to give an edge over heavier competitors in uphill races, which implies a reduction in aerodynamic resistance on the total amount of work being completed $[3,4]$. However, the TT, D, and OD riders of the PC division were significantly different in age. This may demonstrate later success for these athletes due to the need to gain experience in their specialty. The bigger and heavier riders, TT and $\mathrm{S}$, on the other hand, have advantages over the $\mathrm{GC}$ riders such as lower BSA $\mathrm{BM}^{-1}$ and $F A \cdot B M^{-1}$ ratios [2]. In contrast, the $\mathrm{GC}$ riders were lighter in mass which reduces the inhibitory effects of gravity while riding uphill implying a faster climbing speed and which would minimize the influence of aerodynamic resistance on the total amount of work performed [2,13]. However, riders with greater body mass may benefit from lower aerodynamic resistance which results in a lower energy cost per unit of body mass [13]. Olds et al. reported there is a positive relationship between height and body size with $26 \mathrm{~km}$ TT performance [10]. Similarities were found in our study with previous studies for anthropometric characteristics in WT riders illustrating that riders have not changed in nearly two decades $[2,5,6,7]$.

There are limitations in the present study that need to be addressed. The data was obtained from a website that captures available data on professional riders from their team's websites. The values for height and weight may not be correct at the time of data collection. Secondly, the method to determining the rider's specialty was based upon the greatest number of the PCS points. PCS points are established by the website during races and each rider has the ability to be awarded points based upon placing during the race and 
at the conclusion, so a rider can receive points for sprinting although they are not a sprinter.

\section{Practical applications}

Identification of anthropometric characteristic a rider has will benefit the sports directors and coaches in cycling. Through understanding these characteristics, the roles each rider plays on the team can be assigned and may ensure the role of the rider is the most appropriate for their specialty. The present study helps to identify specific anthropometric characteristic differences between the different specialty types of professional cyclists within the WT and PC. However, there are no differences overall between the WT and PC riders.

\section{Acknowledgements}

The authors would like to acknowledge ProCyclingStats.com for the ability to gather the data for this study.

\section{Conflict of Interest}

The authors have no personal or financial relationships with other people or organizations that could have inappropriately influenced this work.

\section{References}

1. Menaspa P, Rampinini E, Bosio A, Carlomagno D, Riggio M, Sassi A. Physiological and anthropometric characteristics of junior cyclists of different specialties and performance levels. Scand J Med Sci Sports. 2012;22:392-8.

2. Padilla S, Mujika I, Cuesta G, Goiriena JJ. Level ground and uphill cycling ability in professional road cycling. Med Sci Sports Exerc. 1999;31:878-85.

3. di Prampero PE, Cortili G, Mognoni P, Saibene F. Equation of motion of a cyclist. J Appl Physiol Respir Environ Exerc Physiol. 1979;47:201-6.

4. Swain DP. The influence of body mass in endurance bicycling. Med Sci Sports Exerc. 1994;26:58-63.

5. Lucia A, Joyos H, Chicharro JL. Physiological response to professional road cycling: Climbers vs. Time trialists. Int J Sports Med. 2000;21:505-12.

6. Sallet P, Mathieu R, Fenech G, Baverel G. Physiological differences of elite and professional road cyclists related to competition level and rider specialization. J Sports Med Phys Fitness. 2006;46:3615.

7. Mujika I, Padilla S. Physiological and performance characteristics of male professional road cyclists. Sports Med. 2001;31:479-87.

8. Brunkhorst L, Kielstein H. Comparison of anthropometric characteristics between professional triathletes and cyclists. Biol Sport. 2013;30:269-73.

9. Du Bois D, Du Bois EF. Clinical calorimeter: A formula to estimate the aprroximate surface area if height and weight be known. Arch Intern Med. 1916;17:863-871.
10. Olds TS, Norton KI, Lowe EL, Olive S, Reay F, Ly S. Modeling road-cycling performance. J Appl Physiol (1985). 1995;78:1596-611.

11. Lucia A, Hoyos J, Chicharro JL. Physiology of professional road cycling. Sports Med. 2001;31:325-37. 12. Foley JP, Bird SR, White JA. Anthropometric comparison of cyclists from different events. Br J Sports Med. 1989;23:30-3.

13. Swain DP, Coast JR, Clifford PS, Milliken MC, Stray-Gundersen J. Influence of body size on oxygen consumption during bicycling. J Appl Physiol (1985). 1987;62:668-72. 